\title{
Produtividade e concentração de amido em batata-doce em função da aplicação de potássio
}

\section{Productivity and concentration of starch in sweet potatoes due to the potassium application}

\author{
Graziella dos Santos Portes Silva' \\ Juliano Tadeu Vilela de Resende ${ }^{2}$ \\ Josue Clock Marodin ${ }^{3}$ \\ Nathalia Campos Vilela Resende ${ }^{4(*)}$ \\ Sonia Maria Kurchaidt ${ }^{5}$
}

\section{RESUMO}

O trabalho teve como objetivo avaliar as características agronômicas da batata-doce, a concentração de amido e o potencial de rendimento de álcool em função da aplicação de doses de potássio via solo. $\mathrm{O}$ experimento foi conduzido em casa de vegetação em delineamento experimental inteiramente casualizado, sendo cinco doses de $\mathrm{K}_{2} \mathrm{O}(0,100$, 200,300 e $\left.400 \mathrm{~kg} \mathrm{ha}^{-1}\right)$. Avaliou-se o teor de potássio na parte aérea, a produção de parte aérea, a concentração de amido, a produtividade de raiz e rendimento potencial de álcool. Mediante os resultados, foi encontrada maior produtividade de raízes de batata-doce, 21,2 $\mathrm{t} \mathrm{ha}^{-1}$, quando aplicado $294 \mathrm{~kg}$ de $\mathrm{K}_{2} \mathrm{O} \mathrm{ha}{ }^{-1}$. A máxima concentração de amido na raiz foi obtida na dose de $267 \mathrm{~kg}$ de $\mathrm{K}_{2} \mathrm{O} \mathrm{ha}{ }^{-1}$. Entretanto, o máximo rendimento potencial de etanol foi obtido na dose de $270 \mathrm{~kg}$ de $\mathrm{K}_{2} \mathrm{O} \mathrm{ha}^{-1}$, demonstrando, assim, que a adubação com potássio promoveu melhor desenvolvimento vegetativo e produtivo de plantas de batata-doce. Além disso, promoveu a melhora da qualidade industrial pela elevação na concentração de amido nas raízes e rendimento potencial de etanol, concluindo-se que o fornecimento do íon potássio contribuiu para o rendimento de componentes biométricos e produtivos na cultura da batata-doce.

Palavras-chave adicionais: Ipomoea batatas (L.); álcool; processamento; nutrição de plantas.

\section{ABSTRACT}

This study aim to evaluate the production of sweet potato roots, the starch concentration and the potential of yield of alcohol in function of the application of potassium doses

I Ms.; Química; Universidade Estadual do Centro Oeste, Unicentro, Campus Cedeteg; Endereço: Rua Simeão Camargo Varela de Sá, 03, CEP: 85040-080, Guarapuava-PR, Brasil; E-mail: graziportes@gmail.com

2 Dr.; Engenheiro Agrônomo; Universidade Estadual do Centro Oeste, Unicentro, Campus CEDETEG; Endereço: Rua Simeão Camargo Varela de Sá, 03, CEP: 85040-080, Guarapuava-PR, Brasil; E-mail: jvresende@uol.com.br

3 Dr.; Engenheiro Agrônomo; Universidade Estadual do Centro Oeste, Unicentro, Campus CEDETEG; Endereço: Rua Simeão Camargo Varela de Sá, 03, CEP: 85040-080, Guarapuava-PR, Brasil; E-mail: josuemarodin@hotmail.com

4 Engenheira Agrônoma; Universidade Federal de Lavras, Campus Universitário; Endereço: Aquenta Sol, CEP: 37200-000, Lavras-MG, Brasil. E-mail: nathcvr@gmail.com. (*) Autor para correspondência

5 Dra.; Matemática; Universidade Estadual do Centro Oeste, Unicentro, Campus Cedeteg; Endereço: Rua Simeão Camargo Varela de Sá, 03, CEP: 85040-080, Guarapuava-PR, Brasil; E-mail: sonia@unicentro.br

Recebido para publicação em 23/02/2017 e aceito em 22/07/2019

\begin{tabular}{llllll}
\hline Ambiência & Guarapuava (PR) & v.15 n.2 & p. 308-322 & Maio/Ago 2019 & ISSN I808 - 025I
\end{tabular}


in the soil. The experiment was conducted in a completely randomized design with five doses of $\mathrm{K}_{2} \mathrm{O}\left(0,100,200,300 \mathrm{e} 400 \mathrm{~kg} \mathrm{ha}^{-1}\right)$. Among the evaluated elements there is the potassium content in aerial part production, starch concentration and root productivity. Through the results the highest productivity of sweet potato roots was $21.2 \mathrm{t} \mathrm{ha}^{-1}$ in the dose of $294 \mathrm{~kg}$ of $\mathrm{K}_{2} \mathrm{O} \mathrm{ha}{ }^{-1}$. The highest concentration of starch in the aerial part was obtained in the dose of $267 \mathrm{~kg}$ of $\mathrm{K}_{2} \mathrm{O} \mathrm{ha}^{-1}$. However the maximum ethanol yield was obtained at a dose of $270 \mathrm{~kg}$ of $\mathrm{K}_{2} \mathrm{O} \mathrm{ha}{ }^{-1}$ demonstrating that the potassium fertilization promoted a better vegetative and productive development of sweet potato plants. In addition, it promote the improvement of industrial quality by increasing the starch concentration in the roots and the potential yield of ethanol, concluding that the supply of potassium ion contributes to the yield of biometric and productive components in the sweet potato crop.

Keywords:. Ipomoea batatas, alcohol, processing, plant nutrition,

\section{INTRODUÇÃO}

A batata-doce (Ipomoea batatas Lam) é uma hortaliça tuberosa de ampla adaptabilidade, cultivada em todo o território brasileiro. Possui múltiplos usos, podendo ser destinada à alimentação humana, processada industrialmente, nas formas de amido, farinha, alimentação animal e como alternativa na produção de álcool (Xianglin, 2004; Momenté et al., 2004; Centro Internacional de La Papa - CIP, 2005).

Mediante a escassez das fontes de energia não renováveis, o desafio de alterar as fontes energéticas tornou-se uma necessidade global. Diversos trabalhos realizados atualmente buscam a descoberta e o aprimoramento das fontes energéticas renováveis. Posto isso, a batata-doce (Ipomoea batatas L.) apresenta características favoráveis como fonte alternativa de energia na produção de álcool.

As raízes tuberosas apresentam em torno de $40 \%$ de massa seca, com 75 a $90 \%$ de carboidratos totais, principalmente açúcares e amido, possuindo, assim, capacidade de produzir até 200 litros de álcool por tonelada de batata-doce (Santana et al., 2013). Esses valores demonstram sua superioridade em relação à cana-de-açúcar, principal matéria prima na fabricação de álcool no Brasil, com produção média de 120 litros de álcool por tonelada de cana-de-açúcar. Segundo Ray e Tomlins (2010), a batata doce é mais eficiente em quantidade de energia liquida produzida por uma unidade de área de tempo se comparada a culturas como arroz, milho e sorgo.

De acordo com publicações da EMPRABA Hortaliças (Silva et al.,2004), tal superioridade é devida ao fato de a batata doce produzir grande volume de raízes em um ciclo relativamente curto. Além disso, a batata doce, apresenta rusticidade no campo, adaptação às condições tropicais e subtropicais e alto rendimento de biomassa por unidade de área bem como álcool de excelente qualidade, semelhante ao álcool de cereais em sua composição química (Gonçalves Neto et al., 2011; Martins et al., 2012).

No âmbito da produção de álcool, a batata-doce ainda é pouco utilizada no Brasil, entretanto, é a espécie vegetal que apresenta maiores potenciais de uso para tal finalidade. No entanto, a batata-doce como alternativa energética enfrenta algumas limitações de ordem fitotécnica. Algumas cultivares não apresentam as características para viabilizar a sua exploração em larga escala como fonte de álcool em bases sustentáveis e de baixo custo.

Dentre as características mais importantes para tornar um clone viável para a produção de álcool destaca-se elevada produção de biomassa nas raízes, alta densidade, alta porcentagem de amido, alta 
produção de álcool por tonelada de raízes e alto rendimento potencial de álcool ( $\left.\mathrm{L} \mathrm{ha}^{-1}\right)$. Portanto, é uma cultura que exige pesquisas na área fitotécnica visando aprimorar as formas de manejo. A recomendação de adubação da batata-doce é uma das formas de manejo que deve ser estudada, objetivando melhorar a produtividade e a qualidade nutricional/industrial, com maior teor de carboidratos totais, viabilizando a produção de biocombustíveis utilizando batata-doce como matéria prima.

O potássio $(\mathrm{K})$ é considerado o nutriente de maior extração pelas plantas de batata-doce (Brito et al., 2006). Sendo assim, para a produção de 11 a $15 \mathrm{t} \mathrm{ha}^{-1}$ de raízes a exigência é de 100 a $236 \mathrm{~kg} \mathrm{ha}{ }^{-1}$ de $\mathrm{K}_{2} \mathrm{O}$ (Silva et al., 2002). A adubação adequada de potássio resulta em maior produtividade (Foloni et al., 2013) e maior produção de açúcares totais e amido. Esse fato devese às funções vitais do potássio para o metabolismo da planta, como na fotossíntese, ativação enzimática, abertura de estômatos, alteração do potencial osmótico, melhora da eficiência de uso da água, síntese de carboidratos como amido e açúcares, translocação de carboidratos nas plantas e acúmulo nos órgãos de reserva (Echer et al., 2009, Marschner, 2012, Corrêa et al., 2014). Thumé et al., (2013) observaram a exportação de até $440 \mathrm{~kg} \mathrm{ha}^{-1}$ de K pelas raízes tuberosas, essa quantidade foi superior à quantidade de potássio aplicado como adubação, resultando em balanço negativo.

Com a recente seleção de genótipos de batata-doce com aptidão à produção de biocombustíveis, tem-se a necessidade de novos estudos sobre a nutrição dessas plantas (Silveira et al.,2007; Camargo et al.,2013;). O aumento da dose de potássio pode resultar maior produtividade e maior concentração de carboidratos totais nas raízes tuberosas e, consequentemente, maior potencial de rendimento de álcool.

Tendo em vista a importância da diversificação da matriz bioenergética que pode ser uma nova oportunidade de emprego e geração de renda, a busca por novas fontes de matérias primas para produção de etanol deve ser estudada de forma a oferecer mais opções às diferentes realidades de solo e clima do país.

Nesse contexto, a elucidação das necessidades nutricionais da batata-doce, em especial o potássio, se configura como importante objeto de estudo, tendo em vista o potencial de produção de energia desta espécie.

Objetivou-se, portanto, com a presente pesquisa avaliar características agronômicas de plantas de batata-doce, a concentração de amido das raízes e rendimento de álcool em função de doses de potássio aplicadas via solo.

\section{MATERIAL E MÉTODOS}

O experimento foi realizado no setor de Olericultura do Departamento de Agronomia da Universidade Estadual do Centro-Oeste/UNICENTRO, em Guarapuava, Paraná. Coordenadas geográficas $25^{\circ} 41^{\prime} 12$ ”S de latitude, 51³8'45”W de longitude e $1.100 \mathrm{~m}$ altitude. Em casa de vegetação com cobertura plástica transparente. No período de novembro de 2011 a abril de 2012.

Para testar as doses de potássio foi utilizado acesso UGA 118. Esse material é proveniente da coleção de batata-doce da UNICENTRO, e foi previamente selecionado para produção de raízes e alto teor de carboidratos totais, com aptidão para a produção de álcool. As mudas foram feitas a partir de estacas de $15 \mathrm{~cm}$, plantadas em bandejas de polipropileno de 72 células, preenchidas com substrato comercial Plantmax ${ }^{\circledR}$.

Os tratamentos foram constituídos de cinco doses de $\mathrm{K}_{2} \mathrm{O}$, sendo elas 0, 100, 200, 300, $400 \mathrm{~kg}$ de $\mathrm{K}_{2} \mathrm{O} \mathrm{ha}{ }^{-1}$. $\mathrm{O}$ delineamento experimental foi em blocos inteiramente casualizados, 
com 5 repetições por tratamento. Cada parcela foi constituída por "piscinas" impermeabilizadas com polipropileno de 100 micras com medidas de 2,00 x 3.00 x $0.40 \mathrm{~m}$ (de 2,4 m³) contendo 30 mudas em três linhas, espaçadas $0,6 \mathrm{~m}$ entre linhas e $0,3 \mathrm{~m}$ entre plantas.

Para preenchimento das piscinas, utilizou-se solo cultivado, $0-20 \mathrm{~cm}$ de profundidade, peneirado em malha de $4 \mathrm{~mm}$, classificado como Latossolo Bruno Álico Distrófico (Embrapa 2013). Foi realizada análise do solo e este apresentou-se com $\mathrm{pH}\left(\mathrm{CaCl}_{2}\right) 5,1$; massa orgânica, 34,9 $\mathrm{g} \mathrm{kg}^{-1}$; P (Mehlich) 7,0 mg dm-3; K 0,6 cmolc dm${ }^{-3}$; Ca 2, 4 cmolc dm ${ }^{-3}$; Mg 1,2 cmolc dm$^{-3}$; $\mathrm{Al}+\mathrm{H}, 3,6 \mathrm{cmolc} \mathrm{dm}^{-3}$; e saturação por bases (V\%), 54\%. Foi utilizado calcário agrícola calcítico para elevação da saturação de bases para 70\%, dois meses antes do plantio das mudas. Após esse período, foi aplicado $160 \mathrm{~kg}$ de $\mathrm{P}_{2} \mathrm{O}_{5} \mathrm{ha}^{-1}$, utilizando superfosfato triplo.

As doses de $\mathrm{K}_{2} \mathrm{O}$ foram aplicadas de forma parcelada, em seis vezes ao longo do experimento, a cada 30 dias, iniciando-se 10 dias após o transplante das mudas de batata-doce. Durante o experimento foi aplicado um total de $100 \mathrm{~kg}$ de $\mathrm{N} \mathrm{ha}^{-1}$ na forma de ureia divididas em 4 vezes, a cada 30 dias. A irrigação foi realizada por sistema de micro-aspersão, com turno de rega que variaram de 15 a 20 minutos, de acordo com as condições climáticas e o estádio de desenvolvimento da cultura, de modo que o solo permanecesse na sua capacidade de campo, e evitando o excesso de água. Não foi necessário realizar aplicações para controle fitossanitário, tendo em vista a não proliferação de patógenos no ensaio.

A colheita foi realizada aos 180 dias após o transplante das mudas, período caracterizado pela maturação fisiológica da batata-doce. Para determinação das características de produtividade foi avaliado rendimento de raiz, pela massa de todas as raízes, e massa fresca de parte aérea, valores expressos em $\mathrm{t} \mathrm{ha} \mathrm{a}^{-1}$. Amostras da parte aérea e das raízes foram lavadas e secas em estufa de circulação forçada a ar $\left(65^{\circ} \mathrm{C}\right)$ até massa constante. Foi determinada a massa seca de parte aérea, pela percentagem da massa seca em relação à massa fresca, valores expressos em percentagem (\%). Em amostras da parte aérea, foi determinado o teor de $\mathrm{K}$ conforme metodologia descrita por Silva (2009), valores expressos em $\mathrm{g} \mathrm{kg}^{-1}$ de K.

As amostras de raízes foram cortadas e trituradas em liquidificador e secas em estufa com circulação forçada de ar. Após o material seco, foi desintegrado em moinho de facas (tipo WILLYE modelo TE 650 marca TECNAL) até a obtenção da farinha. Nas amostras de raízes foi determinada a concentração de amido (CAR) pelo método Eynon/Lane (Cereda et al., 2004), valores expressos em percentagem (\%).

O rendimento potencial de álcool $\left(\mathrm{L} \mathrm{ha}^{-1}\right)$ foi estimado a partir de conversão da concentração de amido nas raízes frescas por meio da multiplicação do fator "6,6", descrito por Silveira (2008) para obtenção de litros de etanol por tonelada de raiz, e multiplicado pela produtividade de raiz.

Estimaram-se os erros associados aos tratamentos para as variáveis respostas e, posteriormente, submeteram-se esses erros ao teste dos pressupostos básicos da análise de variância, visando testar a normalidade por Shapiro Wilk $(\mathrm{P}<0,05)$ e a homogeneidade das variâncias por Luene $(\mathrm{P}<0,05)$. Após verificadas a normalidade e homogeneidade dos dados, estes foram submetidos à análise de variância e, quando constatada significância, foi realizada análise de regressão para as doses de potássio, pelo programa SISVAR (Ferreira, 2014). Os dados foram derivados para regressão em modelo quadrático sendo a escolha do modelo de regressão baseada na significância dos coeficientes de regressão e no maior valor do coeficiente de determinação.

\section{RESULTADOS E DISCUSSÃO}

As hortaliças são exigentes em K disponível no solo, sendo esse o primeiro macronutriente em ordem de extração, para a maioria delas. O potássio favorece a formação e translocação de 
carboidratos e o uso eficiente da água pela planta; equilibra a aplicação de nitrogênio e melhora a qualidade do produto e, consequentemente, o valor de mercado (Marodin et al, 2010). Em batata-doce, a deficiência desse nutriente causa redução da produção comercial devido à maior formação de raízes pequenas e irregulares (Mendonça, 1991).

As adubações com potássio apresentaram efeito positivo nas características agronômicas das plantas de batata-doce, sendo esse efeito devido à maior disponibilidade e absorção desse nutriente. Com o aumento das doses de $\mathrm{K}_{2} \mathrm{O}$, foi observado aumento do teor de potássio na parte aérea das plantas de batata-doce. $\mathrm{Na}$ dose de $287,8 \mathrm{~kg} \mathrm{ha}^{-1}$ de $\mathrm{K}_{2} \mathrm{O}$, observou o maior teor de potássio na planta, no valor de $24,1 \mathrm{~g} \mathrm{~kg}^{-1}$ (Figura 1). Em experimento com batata doce, Foloni et al., (2013) constatou que o teor de potássio foliar foi responsivo à adubação potássica via solo, com ajuste quadrático, ou seja, o máximo teor de $\mathrm{K}$ foliar de $13,62 \mathrm{~g} \mathrm{~kg}^{-1}$ foi alcançado com 92 $\mathrm{kg}$ de $\mathrm{K}_{2} \mathrm{O} \mathrm{ha}^{-1}$. A diferença observada entre a presente pesquisa e os resultados encontrados por Foloni et al., (2013), pode ser em decorrência da cultivar utilizada ou até mesmo do ambiente de avaliação. Entretanto, os resultados de ambas as pesquisas demonstram a relação da adubação com potássio e seu incremento na parte aérea.

\section{Figura 1. Teor de potássio na parte aérea de batata-doce em função da dose de potássio.}

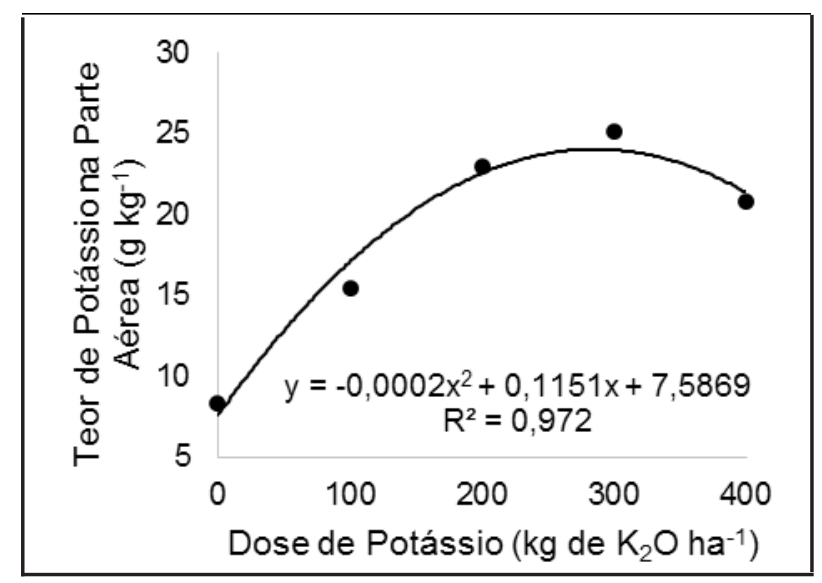

A adubação de potássio promove equilíbrio na absorção de nutrientes, como nitrogênio, fósforo, cálcio, magnésio e enxofre (Foloni et al., 2013, Thumé et al., 2013) acompanhando a mesma tendência de extração e acúmulo na massa seca de parte aérea, promovendo o crescimento da planta. $\mathrm{O}$ aumento das doses de potássio na batata-doce promoveu o crescimento da parte aérea da planta o que resulta no incremento da área fotossintética, resultando em maior eficiência e acúmulo de fotoassimilados nos tecidos de reserva, no caso da batata-doce de amido e açúcares redutores na raiz tuberosa.

Foi observado efeito quadrático das doses de potássio em relação à massa fresca e massa seca de parte aérea. Com a adubação na dose de $250,9 \mathrm{~kg} \mathrm{ha}^{-1}$ de $\mathrm{K}_{2} \mathrm{O}$, obteve-se o máximo de produção de massa fresca de parte aérea, sendo ela de 50,5 $\mathrm{t} \mathrm{ha}^{-1}$ (Figura 2). Entretanto, foi com a dose de 254,3 $\mathrm{kg} \mathrm{ha}^{-1}$ de $\mathrm{K}_{2} \mathrm{O}$ que houve máximo valor de massa seca de parte aérea, no valor de 20,9\% (Figura 3). Com o aumento da superfície foliar, há uma potencialização de trocas gasosas com meio, permitindo maior absorção de $\mathrm{CO}_{2}$ e fixação no ciclo de Calvin pela Rubisco, 
incrementando a síntese de Trioses-P que são carboidratos simples, precursores da síntese de amido no cloroplasto. Para, além disso, o K atua como regulador osmótico na abertura de estômatos, acelerando o processo e garantindo, consequentemente, maiores trocas gasosas e maior eficiência fotossintética (Thaiz e Ziguer 2013).

Figura 2. Massa fresca de parte aérea de batata-doce em função da dose de potássio.

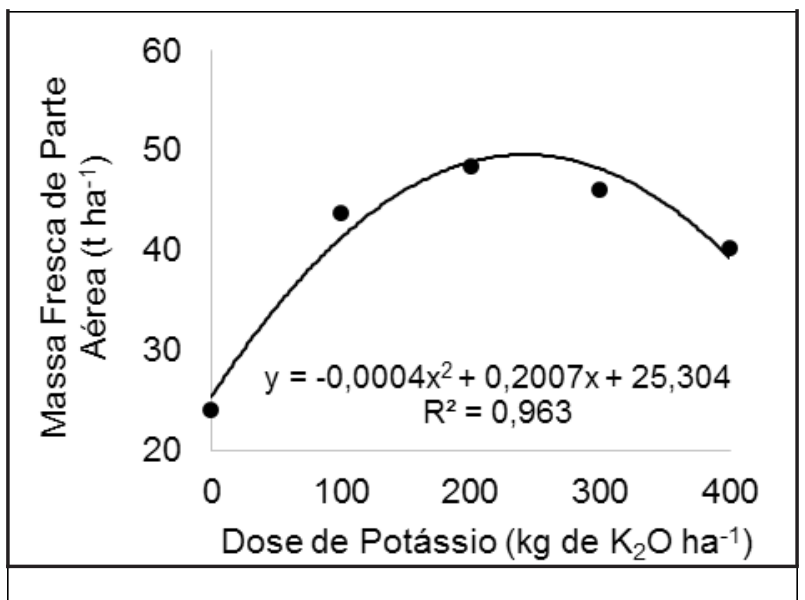

Figura 3. Massa seca de parte aérea de batata-doce em função da dose de potássio. $\mathrm{N}$-nitrate content in soil solution (Y1) and foliar nitrogen (Y2) of 'Top Gun' watermelon... as function to nitrogen rates.

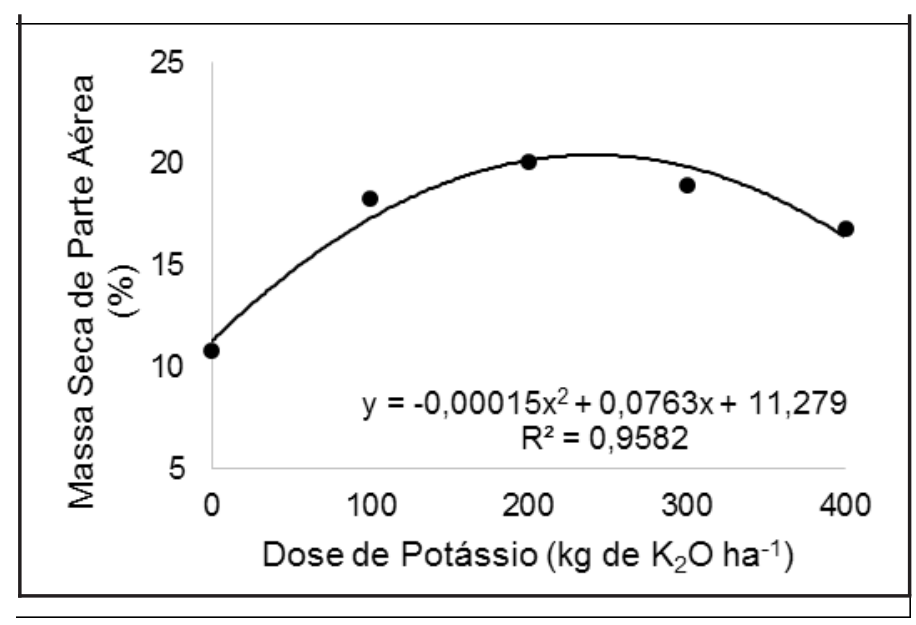

A produção e a translocação de fotoassimilados nas plantas tem revelado uma relação de causa-efeito com a nutrição potássica (HUBER, 1985; MARSCHNER, 2011). O decréscimo da taxa de translocação de fotoassimilados parece anteceder os efeitos da eficiência de potássio sobre as taxas da fotossíntese (HARTT, 1969; ASHLEY e GOODSON, 1972). Esse decréscimo pode estar associado ao requerimento de açúcares, em substituição ao potássio na osmorregulação das folhas (HUBER, 1985). As evidências sugerem que a função do potássio nesse processo é a de promover a liberação ativa da sacarose das células do mesófilo para o apoplasto (DOMAN e GEIGER, 1979; MENGEL, 1974; MAGALHÃES, 2007), provavelmente por meio do 
mecanismo de co-transporte sacarose/K+, ou o carregamento de sacarose do apoplasto para dentro das células companheiras dos elementos crivados (MENGEL, 1974).

Aparentemente, esse carregamento do floema ocorre por um mecanismo de co-transporte sacarose/H+, com o potássio, movendo-se em resposta ao potencial de membrana. Assim a menor eficiência na translocação de fotoassimilados pode elevar os teores de açúcares solúveis e de amido nas folhas (DIAS-FILHO,2006).

Com melhor desenvolvimento da parte aérea, foi observado maior acúmulo de carboidratos totais nas raízes. $\mathrm{O}$ aumento das doses de potássio resultou em maior acúmulo de amido nas raízes, com efeito quadrático, sendo a dose de $266,5 \mathrm{~kg} \mathrm{ha} \mathrm{ha}^{-1}$ de $\mathrm{K}_{2} \mathrm{O}$ que promoveu a máxima concentração de amido na raiz, no valor de $41,1 \%$.

\section{Figura 4. Concentração de amido na raiz de batata-doce em função da dose de potássio.}

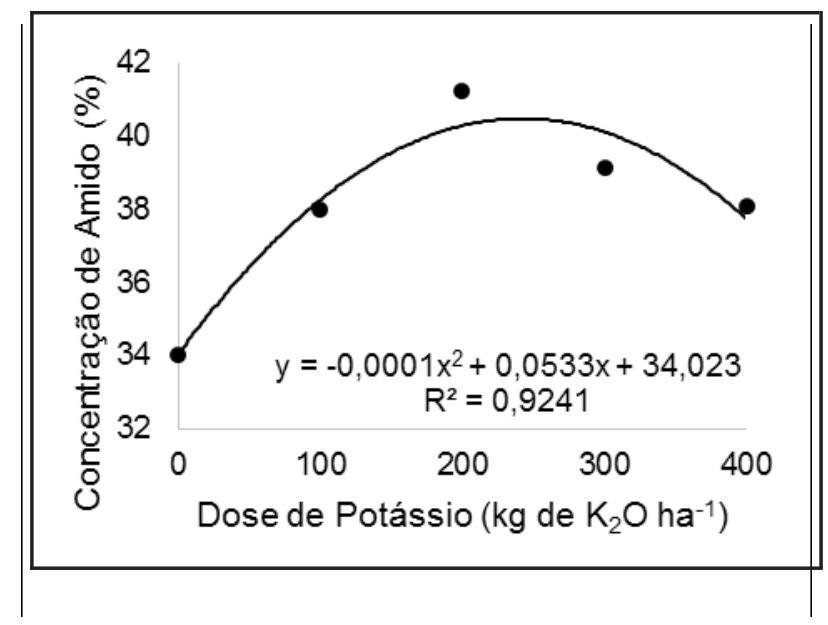

Silveira et al., (2007) avaliaram clones de batata-doce com aptidão para produção de biocombustíveis e observaram concentração de amido de 30,2\% e altas produtividades de raízes tuberosas, $65 \mathrm{t} \mathrm{ha}^{-1}$.

O amido pode ser considerada a principal substância de reserva nas plantas superiores, fornecendo de $70 \%$ a $80 \%$ das calorias consumidas pelo homem. Os depósitos permanentes de amido nas plantas ocorrem, principalmente, nos órgãos de reserva, como é o caso de grãos de cereais (arroz, milho e trigo), de tubérculos e de raízes (batata, mandioca, taro, batata-doce e outras) e de fabáceas (feijão e ervilha) (CEREDA, 2002). Além disso, o amido tem características físicas e químicas e qualidade nutricional superiores, quando comparado com outros carboidratos (WHISTLER; BEMILLER, 1997).

O amido armazenado nas células de sementes, raízes e tubérculos encotra-se depositado na fórmula de grânulos mais ou menos brilhantes, com formas e dimensões diversas, cuja estrutura está intimamente ligada ao seu desenvolvimento na célula viva. Nas células vegetais, os grânulos são formados dentro de estruturas especiais denominadas amiloplastos, envolvidos por uma matriz proteica, o estroma. Os grânulos de amido são estruturas semicristalinas, compostas de macromoléculas lineares e ramificadas, que formam pontes ou ligações de hidrogênio, estando associados paralelamente, o que resulta no aparecimento de regiões cristalinas ou micelares (FRANCO et al., 2001). 
Os resultados obtidos na presente pesquisa estão de acordo com Nogueira et al (1992), que verificaram que os teores de amido e caroteno nas raízes foram influenciados favoravelmente pelos tratamentos com maiores doses de $\mathrm{K}$.

Segundo Malavolta (2006), o potássio é importante para a formação dos açúcares e do amido e para seu transporte até os órgãos de reserva, portanto esse nutriente pode ser considerado como de fundamental importância para cultura da batata-doce, principalmente, no que diz respeito ao aumento dos teores de carboidratos, constituinte fundamental para a produção de álcool.

Neste trabalho, foi observado que a adubação com potássio teve efeito na produtividade de raízes de batata-doce. A produtividade de raiz aumentou em função do aumento das doses de $\mathrm{K}_{2} \mathrm{O}$, em modelo quadrático de regressão. A dose de $294,3 \mathrm{~kg} \mathrm{ha}^{-1}$ de $\mathrm{K}_{2} \mathrm{O}$ proporcionou a máxima produtividade com $21,17 \mathrm{t} \mathrm{ha}{ }^{-1}$ de raízes.

\section{Figura 5. Produtividade de raiz de batata-doce em função da dose de potássio.}

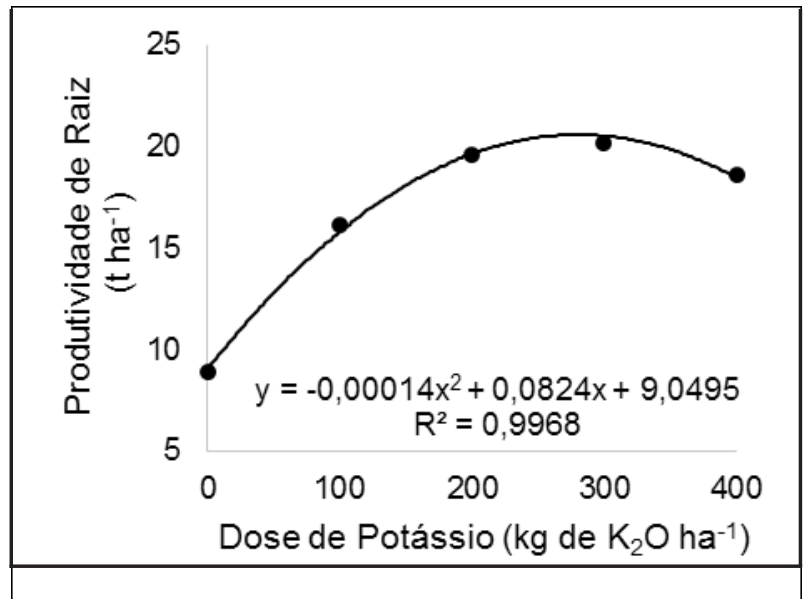

A produtividade de raízes comerciais, embora superior à média nacional, definida em 11,2 t ha $\mathrm{a}^{-1}$ (MAPA, 2005), foi inferior ao rendimento médio de raízes comerciais para a batata-doce encontrados por outros autores (Azevedo et al., 2000; Cardoso et al., 2005; Oliveira et al., 2006; Silveira, 2008), em que a produtividade máxima atingida foi de $65,5 \mathrm{t} \mathrm{ha}^{-1}$, com colheita aos 6 meses. Em contrapartida, os valores médios obtidos estão dentro da amplitude encontrada por Gonçalves, 2011 que variou de 5,40 a 80,74 tha ${ }^{-1}$, valores correspondentes aos clones 2007HSF022-12 e 2007HSF026-01, respectivamente. O valor menor para produtividade encontrado na presente pesquisa pode estar associado à forma de cultivo em "piscinas", o qual restringe o crescimento das raízes.

A produtividade da batata-doce, em resposta à aplicação de potássio é relatada em diversos trabalhos. Foloni et al., (2013) relataram que a maior dose de potássio, $50 \mathrm{~kg} \mathrm{ha}^{-1} \mathrm{de}_{2} \mathrm{O}$, no plantio e $120 \mathrm{~kg} \mathrm{ha}^{-1}$ de $\mathrm{K}_{2} \mathrm{O}$, aplicada em cobertura, resultou em maior produtividade de raízes tuberosas comercializáveis, $24 \mathrm{t} \mathrm{ha}^{-1}$. Echer et al., (2009) verificaram que a dose de $200 \mathrm{~kg} \mathrm{ha}^{-1} \mathrm{de}$ $\mathrm{K}_{2} \mathrm{O}$ resultou em máxima produtividade de batata-doce 27,7 t ha $\mathrm{a}^{-1}$. Brito et al. (2006) verificaram a necessidade de 194 e $173 \mathrm{~kg}$ ha-1 K2O para maximizar a produtividade total (14,8 t ha-1) e produtividade comercial (8,4 t ha-1), respectivamente, em solo com baixo teor de K (37 mg dm3). Também em solos com baixo teor de $\mathrm{K}$, para produzir $12,93 \mathrm{t}$ ha-1 de raízes de batata-doce, Sokoto, Magaji e Sengh (2007) verificaram a necessidade de $150 \mathrm{~kg}$ ha-1 de K (180 kg ha-1 K2O). 
O aumento da produtividade está relacionado às funções do potássio na planta, principalmente pela síntese de carboidratos nas folhas e transporte destes para as raízes tuberosas.

No entanto, doses exageradas de potássio causam efeito negativo sobre o desenvolvimento da batata-doce, além de contaminação do ambiente, devido à salinização e lixiviação. $O$ potássio compete por sítios de entradas no sistema radicular da planta com outros cátions, com efeito antagônico na absorção de cálcio e magnésio, principalmente, onde doses elevadas de potássio pode causar deficiência destes nutrientes. As concentrações de sais próximas às raízes prejudicam a absorção de nutrientes e causam toxidez às plantas. A absorção de sais causa aumento do potencial osmótico e maior absorção de água, com efeito negativo ao metabolismo na planta (Marschner, 1997; Pereira \& Fontes ,2005). Além disso, os sais e potássio podem ser facilmente lixiviados e contaminar lençóis freáticos causando danos ao meio ambiente (Nascimento 2013). Para amenizar o efeito negativo, as adubações de potássio devem ser parceladas no plantio e em cobertura 45 dias após o plantio, período de formação e diferenciação das raízes tuberosas (Echer, 2015).

O rendimento potencial de álcool na cultura da batata-doce em função de doses de potássio, respondeu de forma quadrática, com o ponto máximo de 5.430,6 litros de álcool por hectare na dose de 269,68 $\mathrm{kg} \mathrm{ha}^{-1}$ de $\mathrm{K}_{2} \mathrm{O}$.

\section{Figura 6. Rendimento Potencial de Etanol em função da dose de potássio.}

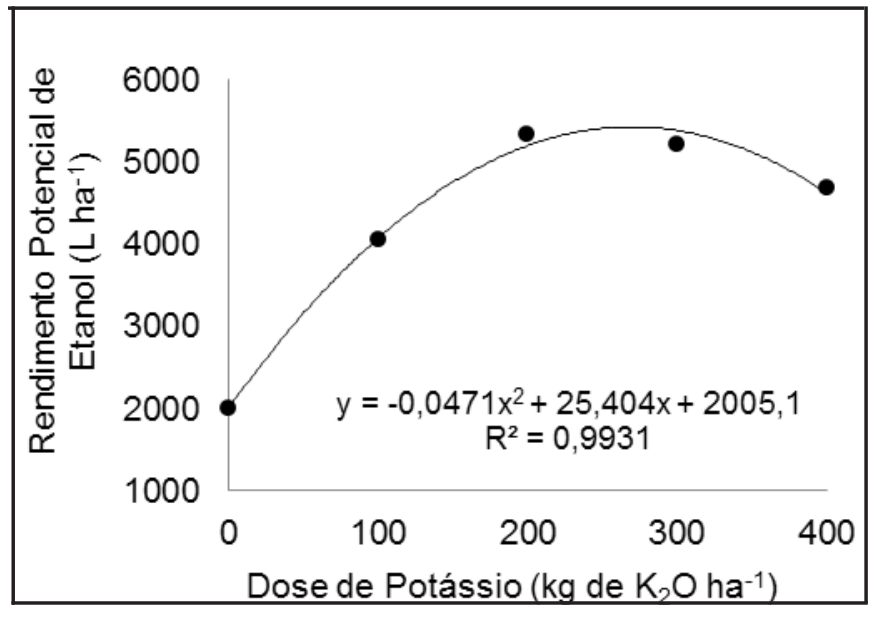

Considerando a capacidade produtiva de álcool de batata-doce, Jones, Hamilton e Dukes (1983) fizeram uma avaliação utilizando as cultivares Jewel e Hi-Dry, tendo sido obtidos de 5.332 a $7.109 \mathrm{~L} \mathrm{ha}^{-1}$ e de 6.660 a $10.663 \mathrm{~L} \mathrm{ha}^{-1}$ de álcool, respectivamente. Porém, esses autores recomendam a adoção de cultivares com maiores teores de massa seca e a melhoria dos processos fermentativos, como meios de se aumentar os rendimentos de álcool.

Outros trabalhos foram realizados, como Collins (1984) que avaliou o rendimento de álcool de nove genótipos de batata-doce, na Carolina do Norte (EUA). Na colheita realizada com 5,5 meses, a cultivare 'Pelican Processor' foi superior em relação ao rendimento de álcool (8.597 $\mathrm{L} \mathrm{ha}^{-1}$ ), com relação de 0,1467 litros de álcool por kg de raízes. Foi verificada correlação positiva entre o teor de massa seca das raízes com o rendimento de álcool ( $\mathrm{r}=0,96$ e p $\leq 0,01)$; em contrapartida, correlação negativa foi encontrada com o teor de proteína $(r=-0,66$ e $p \leq 0,05)$. Em outro experimento, Kim e Hamdy (1985) obtiveram, para a batata-doce cultivar Georgia Red 
$\left(23,6 \% \pm 1,2\right.$ de massa seca e $21,4 \% \pm 0,6$ de amido), produtividade de 30,8 t ha ${ }^{-1}$ de raízes, o que equivale a 4.032 litros de álcool por hectare.

Estudos na Universidade Federal de Tocantins (UFT) selecionaram genótipos de alta produtividade e teor de amido nas raízes, os quais foram avaliados, durante cinco anos, quanto à produtividade de raízes, ao teor de massa seca e amido e ao rendimento de álcool. Destacaram-se as cultivares Duda (65,5 t ha-1 de raízes, 40,4\% de massa seca e $24,4 \%$ de amido), Beatriz (43 t ha-1 de raízes, 33,2\% de massa seca e 26,2\% de amido), Ana Clara (45,7 t ha-1 de raízes, 35,4\% de massa seca e 23,4\% de amido), Amanda (46,7 t ha-1 de raízes, 32,4\% de massa seca e 21,4\% de amido) e Julia (40,6 t ha-1 de raízes, 37,4\% de massa seca e 24,6\% de amido), com produções de 10.467, 7.436, 7.058, 6.595 e 6.585 L ha-1 de álcool, respectivamente, e com custo de produção média de R\$0,42 por litro de álcool produzido (AGÊNCIA PAULISTA DE TECNOLOGIA DOS AGRONEGÓCIOS - APTA, 2011).

Os resultados encontrados no presente trabalho, para rendimento potencial de álcool, se mostraram inferiores aos apresentados nos experimentos relatados. Isso pode ser explicado devido ao fato de se ter utilizado um cultivar diferente o qual foi selecionado para as condições climáticas específicas da região do sul do Brasil. Além disso, as condições nas quais o experimento foi conduzido, ou seja, casa de vegetação, pode ter influenciado no sentido de restringir o potencial produtivo do clone utilizado.

Devido aos avanços do melhoramento genético, e em estudos que veem sendo realizados recentemente, a batata-doce vem se mostrando como um produto potencial para a produção de álcool, além da destinação à alimentação humana e animal. Dentre os fatores que apoiam essa afirmativa, destaca-se o uso crescente da biomassa como propulsor energético moderno, o reconhecimento das vantagens ambientais do uso racional da biomassa de batata-doce e a crescente pesquisa de bioprocessos na biotecnologia (CAMARGO FILHO; et al., 2001). Além disso, sua adaptação aos solos de baixa fertilidade permite a conversão eficiente de energia solar (que é abundante nos trópicos) em carboidratos, sem competir com outras culturas que demandam quantidade maior de nutrientes do solo (MAGALI, 2004). Mediante a sua relativa versatilidade e o fato de ser colhida em períodos de 4 a 6 meses, após plantio, permite aos produtores um melhor aproveitamento das oportunidades de mercado e, em função da demanda, fazer ajustes alternativos dentro das unidades de produção (SOUZA, 2005).

A adoção de técnicas de manejo, como uso racional de fertilizantes, além de aumentar o potencial produtivo da cultura, permite obter um produto de melhor qualidade nutricional e químico, possibilitando maior versatilidade de uso tanto das raízes quanto da parte aérea. Para, além disso, a batata-doce poderia ser cultivada de forma complementar, contribuindo na geração de energia para consumo próprio e ainda prover uma fonte de renda adicional para a agroindústria e outros setores.

\section{CONCLUSÕES}

Para o clone UGA 118, a dose de adubação de $267 \mathrm{~kg} \mathrm{ha}^{-1}$ de $\mathrm{K}_{2} \mathrm{O}$ permite uma melhor qualidade industrial de raízes de batata-doce, apresentando alta concentração de amido no valor de 41\%. Além disso, nessa dose, podem-se obter altas produtividades de raízes de batata-doce. Essas características podem melhorar a eficiência industrial da produção de álcool utilizando batata-doce como matéria prima. 


\section{AGRADECIMENTOS}

Ao Conselho Nacional de Desenvolvimento Científico e Tecnológico (CNPq) pela concessão de suporte financeiro à pesquisa.

\section{REFERÊNCIAS BIBLIOGRÁFICAS}

APTA. Agência Paulista de Tecnologia dos Agronegócios. Disponível em www.apta. sp.gov.br/cana/coletanea/batata-doce_teresa_losada.doc, consultado em 22/03/2011.

ASHLEY DA, RD GOODSON. Effect of time and plant K-status on 14C-labeled photosynthate movement in cotton. Crop Science 12: 686-690,1972

AZEVEDO, S.M.de; FREITAS,J.A.; MALUF,W.R.; SILVEIRA,M.A. da.Desempenho de clones e métodos de plantio de batata-doce. Acta Scientiarum, v.22, p.901-905, 2000.

BRITO, C. H.de; OLIVEIRA, A.P. de; ALVES, A.U.; DORNELES, C. S. M.; SANTOS J. F. dos; NOBREGA, J. P. R. Produtividade de batata-doce em função de doses de K2O em solo arenoso. Horticultura Brasileira, Brasília v. 24, n. 3, p. 320-323, setembro, 2006.

CAMARGO FILHO, W.P., MAZZEI, A.R., ALVES, H.S. Mercado de raízes e tubérculos: análise de preços. Informações econômicas, v.31, n.2, p.36-44, 2001.

CAMARGO, L. K.P. et al. Establishment and molecular characterization of a sweet potato germplasm bank from the highlands of Paraná state, Brazil. Genetics and Molecular Research, v. 3, p. 333-337, 2013

CARDOSO, A.D.et AL. Avaliação de clones de batata-doce em Vitória da Conquista. Horticultura Brasileira, v.23, p.911-914, 2005.

CENTRO INTERNACIONAL DE LA PAPA. CIP sweetpotato facts. Quito, 2005. Disponível em: .Acesso em: 18 Dec. 2009.

CEREDA, M.P. Importância, modo de consumo e perspectivas para raízes e tubérculos de hortícolas no Brasil. In: CARMO, C.A.S. Inhame e taro: sistema de produção familiar. Vitória: Instituto Capixaba de Pesquisa, Assistência Técnica e Extensão Rural, 2002. p.27-32.

COLLINS, W. W. Progress in developing sweet potato (Ipomoea batatas (L.) Lam.) cultivars for fuel alcohol production. In: VI Symposium of the International Society for Tropical Roots and Crops. Proceedings... Lima, p. 571-575, 1984.

DIAS-FILHO, M. B. Respostas morfofisiológicas de Brachiariaspp. ao alagamento do solo e a síndrome da morte do capim marandu. In: BARBOSA, R. A. (Ed.). Morte de pastos debraquiárias. Campo Grande: EMBRAPA Gado de Corte, 2006. p. 83-101 
DOMAN D, DR GEIGER. Effect of exogenously supplied foliar potassium on phloem loading in Beta vulgaris L. Plant Physiol 64: 528-533,1979.

EMBRAPA (2006) Empresa Brasileira de Pesquisa Agropecuária. Centro Nacional e Pesquisa em Solos. Sistema brasileiro de classificação de solos, Brasília. 306p.

BRITO, C.H. et al.Produtividade da batata-doce em função de doses de $\mathrm{K} 2 \mathrm{O}$ em solo arenoso. Horticultura Brasileira, Brasília, v. 24, n. 3, p. 320-323, 2006.

CEREDA, M.P.; DAIUTO,E.R.; VILPOUX, O.Metodologia de determinação de amido por digestão ácida em microondas: método de Lane-Eynon. Associação Brasileira dos Produtores de Amido de Mandioca - ABAM, ano II, n. 8, 2004.

CORRÊA, C. V. et al.Conservação de raízes de batata-doce em função do parcelamento da adubação potássica. Revista Raízes e Amidos Tropicais, v. 10, no 1, p. 65-73, 2014.

ECHER FR; DOMINATO JC; CRESTE JE. Absorção de nutrientes e distribuição da massa fresca e seca entre órgãos de batata-doce. Horticultura Brasileira, Brasília, v. 27, n. 2, p. 176-182, 2009.

ECHER, F.R. Nutrição e adubação da batata-doce. Presidente Prudente: Universidade do Oeste Paulista, 2015. 94p.

FERREIRA, D. F.. Sisvar: a Guide for its Bootstrap procedures in multiple comparisons. Ciênc. agrotec. [online]. 2014, vol.38, n.2 [citado 2015-10-17], pp. 109-112 .

FOLONI,J. S. S. et al. Adubação de cobertura na batata-doce com doses combinadas de nitrogênio e potássio. Semina: Ciências Agrárias, Londrina, v. 34, n. 1, p. 117-126, jan./ fev. 2013

FRANCO, C.M. L. et al. Propriedades do Amido. In: Culturas de Tuberosas Amiláceas Latino Americanas, Propriedades Gerais do Amido. Campinas: Fundação Cargill, 2001. v. 1.

GONÇALVES, R.J.S. Variabilidade genética para produção de etanol e para resistência a Meloidogyne enterolobii em coleção de clones de batata-doce. Tese de Doutorado(Genética e Melhoramento de Plantas) - Universidade Federal de Lavras. 2011.110p.

GONÇALVES NETO, A.C.et al. Aptidões de genótipos de batata-doce para consumo humano, produção de etanol e alimentação animal. Pesquisa Agropecuária Brasileira, Brasília, v. 46, n. 11, p. 1513-1520, 2011.

HARTT, C.E. Effect of potassium deficiency upon translocation of $14 \mathrm{C}$ in attached blades and entire plants of sugarcane. Pldnt Physiol 44: 1461-1469, 1969. 
Huber DM (1985) Session 7: Nutrition and fertilizers. Powelson R Chairperson. Proc 1st Int Workshop on take-all of cereals. In: Parker CA, Rovira AD, Moore KJ, Wong PTW, Kollmorgen JF (eds) Ecology and management of soilborne plant pathogens. American Phytopathol Soc, St. Paul, pp 327-329.

JONES, A; HAMILTON, M. G.; DUKES, P. D. Progress in developing sweet potato (Ipomoea batatas (L.) Lam.) cultivars for fuel alcohol production. In: III Annual Solar Biomass Workshop, Atlanta, 1984. Proceedings... Atlanta, 1984. p. 195-198, 1983.

KIM, K.; HAMDY, M. K. Acid hydrolysis of sweet potato for ethanol production. Biotechnology and Bioengineering, v. 27, n. 3, p. 31-320, 1985.

LEBOURG, C. Brasamide et la fécule: une historie d $\$$ amour. Botucatu: Centro de Raízes Tropicais, UNESP, 1996, 59p.

MAGALI, L .Technical and economical evaluation of the alcohol production from cassava fibrous waste using pectinase as a complementary enzyme. Botucatu ,São Paulo, 2004 . Tese de doutorado em Energia na Agricultura.

MALAVOLTA E. 2006. Manual de nutrição mineral de plantas. São Paulo: Editora Agronômica Ceres. 638p.

MAPA. Ministério da Agricultura, Pecuária e Abastecimento. Culturas - Brasil: produtividade média de lavouras temporárias e permanentes. 2005. Disponível em: <http://www.agricultura.gov.br/ >. Acesso em: 25 de Abril de 2011.

MARODIN J. C.et al.Qualidade físico-química de frutos de morangueiro em função da adubação potássica. Scientia Agraria Paranaensis. Volume 9, número 3 - 2010, p 50-57.

MARSCHNER, H. Mineral nutrition of higher plants. San Diego: 2. ed Academic Press, 1997.

MARSCHNER, P. Marschner's mineral nutrition of higher plants, 3rd edn. Academic, London,2011.

MARSCHNER, P. Marschner's mineral nutrition of higher plants. 3rd ed. New York, Academic Press, 2012, 651p.

MARTINS, E.C.A.et al.Variabilidade fenotípica e divergência genética em clones de batata-doce no estado do Tocantins. Revista Ciência Agronômica, Fortaleza, v. 43, n. 4, p. 691-697, 2012.

McARDLE, R. N.; BOUWKAMP, J. C. Potential of sweet potato as a feedstock for small scale fuel ethanol production. Hortscience, v. 17, n. 3, p. 534, 1982. 
MOMENTÉ, V. V.et al. Seleção de cultivares de batata-doce adaptados à produção de biomassa, via programa de melhoramento, visando à produção de álcool no estado do Tocantins. Horticultura Brasileira, Brasília, v. 22, n. 2, jul. 2004. Suplemento.

NOGUEIRA, F. D. et al. Adubação verde, fosfato natural e gesso para a cultura da mandioca em latossolo roxo textura argilosa. Pesquisa Agropecuária Brasileira, Brasília, v. 27, n. 3, p. 357-372, 1992.

OLIVEIRA, A. P. et al. Produção de raízes de batata-doce em função do uso de doses de $\mathrm{N}$ aplicadas no solo e via foliar. Horticultura Brasileira, 24: 279-282. 2006.

PEREIRA, P. R. G; FONTES, P. C. R. Nutrição mineral de hortaliças In: FONTES, P. C. R. (Ed) Olericultura: Teoria e Prética. Viçosa, UFV. p. 39-35. 2005.

RAY, R. C.; TOMLINS, K. I. Sweet Potato: Post Harvest Aspects In Food,

Feed and Industry. Nova Science Publishers, Inc.: 2010.

SANTANA, W.R.et al. Identificação agronômica de genótipos de batata-doce em banco de germoplasma para fins industriais de etanol carburante. Tecnologia \& Ciência Agropecuária, João Pessoa, v. 7, n. 1, p. 31-34, 2013.

SILVA, F.C. Manual de análises químicas de solos, plantas e fertilizantes. 2. ed. Brasília: Embrapa Informação Tecnológica, 2009.627 p.

SILVA JBC, LOPES CA \& MAGALHÃES JS (2002) Cultura da batata-doce. In: Cereda MP (Ed.) Agricultura: tuberosas amiláceas latino americanas. São Paulo, Cargil. p.449-503.

SILVA, J.E.L. Rendimento e teor de amido da batata-doce em função de doses de P2 O5 e de espaçamentos de plantio. 2004. 68 f. (Dissertação mestrado) - Universidade Federal da Paraíba, Areia

SILVEIRA, M.A.et al. A cultura da batata-doce como fonte de matéria-prima para a produção de etanol. Palmas, Universidade Federal do Tocantins. 45p. 2007 (Boletim Técnico).

SILVEIRA, M. A. Batata-doce: uma nova alternativa para a produção de etanol. In: Instituto Euvaldo Lodi. Álcool combustível. Brasília, 2008. V1, p109-122.

SOKOTO, M.B.; MAGAJI, M. D,; SINGH, A. Growth and yield of irrigated sweet potato (Ipomoea batatas (L) Lam) as influenced by intra row spacing and potassium. Journal of Plant Sciences, Nigéria, v.2, n. 1, p. 54-60. 2007.

SOUZA, A. F. B. C. Avaliação do processo de hidrólise e fermentativo de biomassa de 
batata doce [Ipomoea batatas (L.) Lam] por meio de células imobilizadas para produção de etanol. 2005. Dissertação (Mestrado em Ciências do Ambiente). Universidade Federal do Tocantins, Palmas-TO, 2005.

THUMÉ, M.A.et al. Níveis críticos foliares de nutrientes de três cultivares de batatadoce, selecionados para a produção de etanol1 Rev. Ceres, Viçosa, v. 60, n.6, p. 863-875, nov/dez, 2013

XIANGLIN, L. The livestock revolution and feed demand in China.In: FUGLIE, K.O.; HERMANN, M. (Ed.). Sweetpotato Post-Harvest Research and Development in China. Bogor: International Potato Center, 2004. cap. 3, p. 40-47.

WHISTLER, R.L. ; BEMILLER, J.N. Carbohydrate chemistry for food scientists. Eagen Press, St Paul, 117-151,1997. 